\title{
LA REFERENCIA FRANCESA: ARQUITECTURA Y ARQUITECTOS DESDE LA MIRADA ENCICLOPEDISTA
}

\section{The French Reference: Architecture and Architects in the Encyclopédie}

\author{
Juan CALATRAVA \\ ETS Arquitectura \\ Universidad de Granada \\ jcalatra@ugr.es
}

Fecha de recepción: 10/01/2016

Fecha de aceptación definitiva: 2/09/2016

RESUMEN: El artículo analiza la presencia de las cuestiones arquitectónicas en la Encyclopédie de Diderot y D'Alembert. Esta presencia es irregular y no sistemática, como lo fue la propia obra colectiva, con su amplia pluralidad de voces, pero precisamente por ello puede ser representativa de la diversidad de ideas de los philosopohes sobre arquitectura. La difusión de la Encyclopédie en España permite plantear la hipótesis de que fuese uno de los elementos de referencia del debate arquitectónico en la España de las Luces.

Palabras clave: Arquitectura; Encyclopédie; Francia.

ABSTRACT: This text focuses on the presence of architectural issues and related questions in Diderot and D'Alembert's Encyclopédie. This presence is irregular and non-systematic, as is the Encyclopédie itself, with its plurality of voices, but precisely for this reason, it can be representative of the different ideas of the philosophes about architecture. The diffusion of the Encyclopédie in Spain allows us to posit the hypothesis that it could be a source of the architectural debate in Enlightenment Spain.

Key words: Architecture; Encyclopédie; France. 
Es bien sabido que uno de los hechos más destacados de la renovación de la arquitectura española en la segunda mitad del siglo XVIII es el amplio desarrollo teórico que la acompaña y sustenta ${ }^{1}$. Desde el soporte institucional ofrecido por la Academia de San Fernando y otros ámbitos del aparato de Estado (en especial, el cuerpo de ingenieros militares), personajes clave de las Luces borbónicas como Antonio Ponz, Diego de Villanueva, Eugenio Llaguno, Juan Agustín Ceán Bermúdez, Gaspar Melchor de Jovellanos, José de Hermosilla, José Ortiz y Sanz o Isidoro Bosarte no sólo desempeñaron un importante papel en la política artística y arquitectónica de la monarquía, sino que también fundamentaron, en multitud de textos, la idea de un arquitecto/intelectual fuertemente imbuido de los valores y categorías de pensamiento que habían sido puestas a punto en el seno de las Lumières francesas y que sufrieron en sus escritos un proceso de adaptación a la específica problemática hispana.

Desde este punto de vista, quizás pueda resultar pertinente recordar la condensación que del debate arquitectónico francés, el espejo en el que se miraban los reformistas de toda Europa, ofreció la obra más representativa de la cultura de las Luces, la Enciclopedia. En especial, evocar la gran cantidad de propuestas y líneas que en ella se entrecruzan y desterrar el mito de su carácter cerrado y unitario puede permitirnos también comprender hasta qué punto las teorizaciones hispanas estaban lejos de ser un conjunto hermético y perfectamente solidario, presentando por el contrario un fuerte grado de diferenciación y articulación internas. Este análisis comparativo está aún en gran medida por hacer, ya que, pese a los grandes avances registrados en las tres últimas décadas, queda mucho por saber sobre los detalles y las modalidades de la recepción de las obras francesas en la cultura arquitectónica española.

La gran Encyclopédie ou Dictionnaire raissonné des Sciences, Arts et Métiers ideada por Denis Diderot y dirigida por él mismo y por Jean-le-Rond D'Alembert

1. El conocimiento de la teorización arquitectónica en la España de las Luces ha experimentado un gran avance cuantitativo y cualitativo, generando una copiosa bibliografía que no procede reseñar aquí de manera exhaustiva y de la que me limito a reseñar a continuación algunos hitos especialmente relevantes: BARÓN, Javier. Ideas de Jovellanos sobre la arquitectura. Oviedo: Consejería de Educación, Cultura y Deportes del Principado de Asturias, 1985. SAMBricio, Carlos. La arquitectura española de la Ilustración. Madrid: Consejo Superior de los Colegios de Arquitectos de España-Instituto de Estudios de Administración Local, 1986. SAmBricio, Carlos. Territorio y ciudad en la España de la Ilustración. Madrid: Ministerio de Obras Públicas y Transportes, 1991. LEÓn Tello, Francisco José y Sanz SANZ, M. ${ }^{a}$ Virginia. Estética y teoría de la arquitectura en los tratados españoles del siglo XVIII. Madrid: CSIC, 1994. Rodríguez Ruiz, Delfín. La memoria frágil. José de Hermosilla y Las Antigüedades árabes de España. Madrid: Fundación Cultural COAM, 1992. ÚBEDA DE LOS CoBOS, Andrés. Pensamiento artístico español del siglo XVIII. De Antonio Palomino a Francisco de Goya. Madrid: Museo Nacional del Prado, 2001. Moleón, Pedro. Arquitectos españoles en la Roma del Grand Tour (1746-1796). Madrid: Abada editores, 2003. CREsPo Delgado, Daniel. Un viaje para la Ilustración. El Viaje de España (1772-1794) de Antonio Ponz. Madrid: Marcial Pons, 2012. Rodríguez Ruiz, Delfín (ed.). José de Hermosilla y Sandoval. Badajoz: Diputación Provincial, 2015. 
entre 1750 y 1759, y por Diderot en solitario desde 1759 hasta la finalización de la empresa en la década de 1770, es unanimemente considerada como la más cumplida expresión de los ideales de las Luces y el empeño colectivo en el que mejor cristalizaron los anhelos de la generación de los philosophes. En esta visión hay, sin duda, una muy importante parte de verdad, pero también mucho de tópico repetido una y otra vez sin entrar en el análisis interno de esta magna obra colectiva.

Y es que la Enciclopedia ha sufrido durante largo tiempo los mismos efectos de esa visión reduccionista, por fortuna desterrada ya hace décadas y que contemplaba a "las Luces» como un pensamiento unitario y sin fisuras, casi como una secta de la que habría surgido en filiación directa la Revolución francesa. En el marco de esta visión forzadamente monolítica, que hacía tabla rasa de los múltiples posicionamientos y contradicciones internas de los philosophes, la propia Encyclopédie era también a menudo considerada como un mero compendio de los tópicos ilustrados. Hizo falta toda una revolución historiográfica, a partir sobre todo de los años 1950 y 1960, para dejar sentado -a partir de un gran cúmulo de estudios monográficos que revelaban la asombrosa diversidad de las Lumièresque la Encyclopédie, lejos de ser un cómodo resumen aséptico, era en realidad uno de los principales terrenos en los que se jugaba y se ponía en evidencia la profundísima articulación interna de las Luces y se veía con claridad meridiana el entrecruzamiento de muy diferentes líneas de pensamiento. La monumental tesis doctoral de Jacques Proust ${ }^{2}$ fue sólo el hito más relevante de una eclosión de estudios que pusieron las bases para que se comenzaran a estudiar exhaustivamente los desarrollos enciclopedistas en cada uno de los campos del saber, incluyendo la arquitectura y las bellas artes ${ }^{3}$.

En 1963, en un artículo breve pero cargado de implicaciones para el desa-

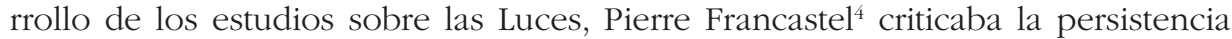
de esta visión monolítica y reclamaba una mirada mucho más articulada que permitiese dar cuenta de toda la riqueza, complejidad y contradicciones internas de una cultura que lo fue todo menos unitaria. Recurría para ello a una metáfora, la de una madeja enrevesada compuesta de muchos hilos, que recordaba la imagen con la que cuatro décadas antes Aby Warburg había simbolizado su nueva idea de la historia del arte: la de un amasijo de serpientes que se retuercen indefinidamente y que escapa a cualquier tentativa de otorgarle una forma definitiva y

2. Proust, Jacques. Diderot et l'Encyclopédie. Paris: Albin Michel, 1962.

3. Calatrava, Juan. La teoría de la Arquitectura y de las Bellas Artes en la Encyclopédie de Diderot y D'Alembert. Granada: Diputación Provincial, 1992.

4. Francastel, Pierre. "L'esthétique des Lumières". En Francastel, Pierre (ed.). Utopie et institutions au XVIIIe siècle. Le pragmatisme des Lumières. Paris-La Haya: Mouton, 1963, pp. 331-357 (traducción castellana "La estética de las Luces». En AA. VV. Arte, arquitectura y estética en el siglo XVIII. Madrid: Akal, 1980, pp. 15-55). 
bien delimitada 5 . Tanto Warburg como Francastel pueden representar, así, una nueva manera de entender la complejidad de los fenómenos históricos, bien lejana a cualquier dogmatismo de Gran Relato. La multiplicación exponencial de estudios monográficos sobre prácticamente todos los aspectos de la Encyclopédie viene permitiendo, finalmente, recuperar una cartografía completa de esta magna empresa, con todos los accidentes de su orografía, sustituyendo a lo que no era sino uno de esos viejos mapas que, como ironizaba Jonathan Swift, suplían con fantasía la ignorancia de la realidad ${ }^{6}$.

De todas estas nuevas investigaciones emerge la idea de una Encyclopédie tenazmente dirigida por Denis Diderot -que supo sortear los innumerables obstáculos políticos y, contra todo pronóstico, culminar los 17 volúmenes de texto y 11 de láminas-, pero compuesta de un cúmulo de colaboradores absolutamente diverso por extracción social, formación intelectual, fama o grado de compromiso con la empresa. Diderot escribió una gran parte de la obra, a menudo de manera anónima, y reclutó a multitud de artesanos, profesionales o figuras menores de la intelectualidad. En cambio, la contribución de algunas de las más consagradas figuras de las Luces fue mínima: Montesquieu aportó sólo un artículo; Voltaire -que siempre miró esta iniciativa colectiva con cierto desapego- 43, y en cuanto a Rousseau se limitó a proporcionar artículos de música, con la notable excepción del gran texto Economie politique. D'Alembert, inicialmente codirector de la obra, se mostró a menudo reticente a arrostrar los grandes riesgos personales que se pusieron de manifiesto en las graves crisis de 1752 y 1759, y en este último año dimitió. Muy pronto se hizo evidente que el campo de los philosophes estaba recorrido por duras querellas internas, como la que enfrentó a Rousseau con D'Alembert y Diderot y llevó a que también en 1759 el ginebrino abandonara su relación con la obra.

Esta azarosa historia interna, verdadera radiografía de la complejidad de las Lumières, afectó también al desarrollo dado a la arquitectura. En principio, el elegido para asumir la parte correspondiente a la arquitectura dentro de este variopinto grupo de intelectuales, científicos, técnicos y artesanos fue Jacques-François Blondel (1705-1774), respetado arquitecto y una de las figuras más influyentes de la arquitectura francesa de la segunda mitad del XVIII ${ }^{7}$. Sin embargo, su abandono en 1759, paralelo al de D'Alembert, llevó a encargarse de los artículos de arquitec-

5. La más completa exposición de las tesis de Warburg, en Didi-Huberman, Georges. La imagen superviviente. Historia del arte y tiempo de los fantasmas según Aby Warburg. Madrid: Abada editores, 2009.

6. «So geographers, in Africa maps, / with savage-pictures fill their gaps, / and other inhabitable downs / place elephants for want of towns" (Salvajes que en mapas africanos / con cuadros de salvajes llenan vanos / y meten en desiertas soledades / elefantes a falta de ciudades", Jonathan Swift, On Poetry: a Rhapsode, 1733; trad. J. L. Arantegui, cit., en SchlÖGEL, Karl. En el espacio leemos el tiempo. Madrid: Siruela, 2007, p. 165).

7. ClEARY, Richard Louis. Jacques-François Blondel and the notion of architectural convenience. Madison: University of Wisconsin, 1977. 
LA REFERENCIA FRANCESA: ARQUITECTURA Y ARQUITECTOS DESDE LA MIRADA ENCICLOPEDISTA

tura a un personaje de enorme interés, del que se hablará más abajo: el Chevalier de Jaucourt.

Comenzando por Jacques-François Blondel, pese a que su obra construida es escasa y periférica, localizándose sobre todo en Metz y Estrasburgo, su labor docente y el amplio eco de su obra teórica le aseguraron un papel fundamental en el panorama de la arquitectura francesa en esos mismos años en los que se estaba gestando la llamada generación "revolucionaria", algunos de cuyos miembros más relevantes (Boullée, Ledoux, Neufforge o De Wailly, por ejemplo) fueron sus discípulos directos.

Como teórico de la arquitectura, Blondel aparece sobre todo como el último gran codificador del clasicismo francés del Grand Siècle y máximo representante de toda una tendencia arquitectónica y cultural que, enfrentada a los excesos ornamentales de lo que hoy conocemos como Rococó (es decir, los desarrollos de la primera mitad del siglo XVIII), a los que estigmatiza como degeneraciones de la recta razón producidas sobre todo por influencias corruptoras externas (en especial, italianas), mira no tanto al futuro, a la construcción de una nueva alternativa arquitectónica, sino al mitificado pasado de la época del Rey Sol.

Esta exaltación de una supuesta edad de oro de la arquitectura francesa, claramente relacionable con la postura expresada por Voltaire en Le siècle de Louis $X I V$, la desarrolló Blondel en una serie de influyentes libros que se escalonan desde De la Distribution des Maisons de Plaisance (1737-1738) hasta el magno repertorio en cuatro volúmenes Architecture Françoise (1752-1756), el ficticio debate epistolar de L'Homme du Monde éclairé par les Arts (1774, póstuma) o, sobre todo, el gran Cours d'Architecture (1771-1776, seis volúmenes, los dos últimos de los cuales, póstumos, fueron revisados por Pierre Patte).

En el terreno de la enseñanza de la arquitectura, Blondel fundó en 1743 la École des Arts, una academia privada de arquitectura que constituyó un verdadero foco de reflexión teórica y profesional, y fue asimismo, a partir de 1755 -es decir, en pleno periodo enciclopedista-, profesor de la Académie Royale. Y, lo que es más importante, puso por escrito en al menos dos ocasiones sus reflexiones teóricas sobre la docencia de la arquitectura: sus Discours sur la manière d'étudier l'architecture et les arts qui sont relatifs à celui de bâtir (1747) y Discours sur la necessité de l'étude de l'architecture (1754) constituyen dos hitos -que he tenido ocasión de estudiar más prolijamente en otro lugar $-^{8}$ en la historia de la docencia de la arquitectura.

Blondel se nos presenta, así, desde el inicio de la andadura enciclopedista, como un profesional de alto nivel y gran reputación intelectual, bien situado en el establishment cultural del Paris de 1750, y no cabe duda de que su reclutamiento

8. Calatrava, Juan. "Una propuesta de enseñanza de la arquitectura en la Francia de las Luces: Blondel y la École des Arts». En AA. VV. Estudios dieciochistas en homenaje al profesor José Miguel Caso González. Oviedo: Instituto Feijoo de Estudios del siglo XVIII, 1995, pp. 118-127. 
para la empresa debe ponerse en el haber de D'Alembert, mucho mejor relacionado entre las filas de la intelectualidad parisina que el aún por entonces relativamente desconocido y más marginal Diderot.

Entre 1750 y 1759 Blondel proporcionó para los siete primeros volúmenes de la Encyclopédie unos 500 artículos sobre arquitectura, de extensión e importancia muy desigual. Sin embargo, en 1759, coincidiendo con la segunda gran crisis de la empresa, que determinó el abandono de la misma por parte de D'Alembert y muchas de las figuras que su prestigio había atraído, su colaboración practicamente se extingue: aunque aún aparecerán algunos artículos en los volúmenes VIII, X y $\mathrm{XI}$, así como, más tarde, los comentarios a las planches de arquitectura, se trata sin duda de textos previamente entregados. En suma, el año de 1759, la mayor cesura en la historia de la Encyclopédie, constituye una bisagra también en el ámbito de la teorización arquitectónica.

La de Blondel es, pues, una contribución fragmentaria, que aspiraba a ser un nuevo tipo de tratado de arquitectura, accesible al público común ilustrado y no sólo a los especialistas, pero que quedó subitamente cercenado. Por mor del puro orden alfabético, Blondel nunca llegó a escribir artículos que podemos sospechar que hubiesen desempeñado un papel relevante, como por ejemplo Ordres, Palais, Symmétrie, Thèâtre, Temple, Ville, etc. Sin embargo, esta fragmentariedad no resta importancia al Blondel enciclopedista, ya que, por un lado, nos es factible reconstruir el conjunto de su visión teórica acudiendo a su Cours d'Architecture (aunque los dos últimos volúmenes se publicaran postumamente) y, por otro, su abandono de 1759 no deja de ser un síntoma clamoroso de las importantes contradicciones internas de una empresa colectiva marcada por profundas divisiones y que constituía, en el fondo, todo un microcosmos en el que coexistían forzadamente muchos de esos hilos de la madeja de que hablaba Francastel.

La imagen que de la arquitectura se transmite en la Encyclopédie a partir de los textos de Blondel es la de una actividad humana esencial para el progreso y la felicidad de los hombres y para la fama de gobernantes y naciones. Una actividad que debe estar, sobre todo, dominada por la síntesis ponderada entre razón e imaginación, entre reglas y genio, entre naturaleza y cultura: elementos sólo en apariencia opuestos y que el arquitecto, cual moderno alquimista, debe saber combinar en las dosis justas para alumbrar una arquitectura que sea a un tiempo racional y creativa. Con ello Blondel no hacía sino alinearse con la tesis ampliamente dominante entre todos los colaboradores de la Encyclopédie: la que persigue la entronización de la Razón, como palanca primordial para alumbrar la nueva época de Luz, pero considera al mismo tiempo necesario que ese otro componente humano constituido por las pasiones esté embridado (la metáfora equina es recurrente), pero no anulado. Los poderes de la imaginación aseguran la creatividad y alejan el peligro de un exceso de sequedad racional, pero al mismo tiempo son poderes peligrosos, siempre en la frontera de lo excesivo y lo incontrolable. El gran reto del creador -en este caso, el arquitecto- será, pues, el de asegurarse sus servicios en un plano de sumisión y control. 
Es así como en el artículo Architecte ${ }^{9}$, Blondel aplica a la caracterización de la figura del arquitecto todas las aporías de la visión enciclopedista del genio (explicitada sobre todo en el artículo Génie ${ }^{10}$, de Saint-Lambert, pero también en otros muchos textos de la obra) y su conflictiva relación con las reglas. El buen arquitecto debe estar dotado de cualidades naturales como la inteligencia, la invención, el gusto o el «ardor", pero siempre reconducidas dentro del encauzamiento que supone la educación y el aprendizaje de toda una serie de normas que aseguran su anclaje con la naturaleza y ahuyentan el riesgo de caer en los delirios de la fantasía. El arquitecto entra, sin duda alguna, dentro de las filas de los tocados por el génie, pero, como aclara Blondel -unas pocas páginas después en el mismo volumen de la obra, por azares del orden alfabético- también es un hombre de goût, es decir, de esa otra cualidad que no es connatural sino adquirida, que se perfecciona mediante el estudio y que permite atemperar los excesos a que se vería abocado un génie sin control ${ }^{11}$.

La visión de Blondel de la historia de la arquitectura resulta absolutamente coherente con esta búsqueda de la síntesis ponderada entre genio y razón, y se articula además sobre el mito básico que impregna el pensamiento de las Luces: la alternancia de periodos «ilustrados» $\mathrm{y}$ "Oscuros», marcada por un ineluctable progreso que terminará por conducir al triunfo de la Luz (tal y como visualizaba de modo diáfano el frontispicio grabado por Cochin para el volumen I de la Encyclopédie). Pero a ello viene a añadirse, como un tercer pilar, el nacionalismo arquitectónico que, fruto tardío de la famosa querelle des Anciens et des Modernes, impregna toda la teorización de Blondel y le lleva a tratar siempre de fundamentar la superioridad de la arquitectura francesa contemporánea sobre la italiana (presa de excesos irracionales que personifica en su gran bestia negra: Borromini $)^{12}$. Es sobre estos tres parámetros como se construye una idea de la historia de la arquitectura que está ya claramente presente en la Architecture Françoise (estrictamente contemporánea a la colaboración de Blondel en la Encyclopédie), se esboza en algunos artículos de esta última y conocerá un desarrollo más acabado en el Cours d'Architecture.

En esta línea, el artículo Architecture ${ }^{13}$ esboza un recorrido histórico cuyos hitos principales son los momentos en que naturaleza y cultura encuentran su

9. Encyclopédie, vol. I, p. 617 (en adelante, para las citas de artículos de la Encyclopédie, se mencionará tan sólo el volumen y n. ${ }^{\circ}$ de página).

10. VII, 582-584.

11. Artículo Goût (Architecture), VII, 770. La entrada Gôut es una de las más importantes de la reflexión estética y antropológica enciclopedista, ya que bajo esta rúbrica aparecieron largos textos nada menos que de Voltaire (Goût, VII, 761), Montesquieu (Goût. Essai sur le goût dans les choses de la nature et de l'art, VII, 762-767) y D'Alembert (Goût. Reflexions sur l'usage et sur l'abus de la philosophie en matière de goût, VII, 767-770).

12. Sobre la fuerte presencia en la teorización francesa de este verdadero nacionalismo arquitectónico, vid. PÉrouse de Montclos, Jean-Marie. L'Architecture à la Française. XVIe, XVIIe, XVIIIe siècles. Paris: Picard, 1982.

13. I, 617-618. 
mejor acuerdo. La célebre cabaña primitiva, elevada por Laugier al rango de arquetipo de toda arquitectura, es para Blondel sólo un punto de partida que, en las antípodas de lo planteado por Rousseau, hallará su mejor cumplimiento sólo al «civilizarse». Del mismo modo, los órdenes grecorromanos siguen siendo pertinentes para el arquitecto contemporáneo no por acrítica adoración a los Antiguos, sino por representar el laborioso acuerdo perfecto logrado entre un origen natural y un proceso de abstracción a partir de la razón: es por eso por lo que las propuestas de invención de nuevos "órdenes» no son sino gratuitos juegos de imaginaciones desbordadas ${ }^{14}$.

Como era de esperar, las cumbres de esta historia aparecen ocupadas por los arquitectos del clasicismo francés y sus epígonos más contemporáneos, los máximos representantes de esa síntesis ponderada, que copan la lista de ejemplos con los que Blondel ilustra, en Architecte, el paradigma del arquitecto perfecto. Son los arquitectos los que mejor muestran una sana contención decorativa ${ }^{15} \mathrm{y}$, sobre todo, los que sobresalen en lo que constituye para Blondel el punto nodal de la adaptación de la arquitectura a las exigencias concretas del programa: la ciencia de la distribution $^{16}$.

En efecto, desde Lemercier o Perrault hasta Boffrand, Gabriel o François Franque, todos ellos bajo la égida de François Mansart, el modelo inigualable para Blondel, corre una línea francesa que ha terminado por superar la hegemonía italiana. El fracaso de Bernini en el Louvre y, sobre todo, las excentricidades nocivas de Borromini y su secta provocan una dura censura sobre la arquitectura del otro lado de los Alpes: tan sólo la arquitectura romana y las mejores obras del Renacimiento pueden seguir sirviendo de modelo, y eso es justamente lo que vuelve ya peligroso el viaje a Italia, pieza esencial hasta entonces de la formación del arquitecto y que Blondel no llega a cuestionar por completo, pero sí a rodear de todo tipo de cautelas.

Pero este esquema evolutivo no es tan diáfano como quisiera Blondel, ya que se ve distorsionado por un momento histórico que empaña la claridad del discurso: el de la arquitectura gótica. La gran cuestión del gothique des Lumières no es privativa de Blondel, sino que se convierte en uno de los grandes caballos

14. Esta reflexión sobre los órdenes clásicos tiene un ulterior desarrollo en otro artículo de Blondel, Colonne (III, 651-652), un texto de gran interés a la hora de comprobar hasta qué punto resultaba ya obsoleta la vieja querelle des Anciens et des Modernes e iba siendo sustituida por preocupaciones más modernas, sobre todo las relacionadas con la exigencia de una fuerte contención en los aspectos ornamentales de la arquitectura. También en el artículo Chapiteau (III, 179) reafirma Blondel la idea de que en los cinco órdenes clásicos cristalizan los grandes modos naturales de construir, y no se trata de meras invenciones a las que siempre sería posible añadir otras nuevas variando simplemente los ornamentos.

15. Esa exigencia de que la decoración sea "natural" y dictada por la razón y huya de cualquier tipo de exceso ornamental es el gran tema del largo artículo Décoration (IV, 702-704), que será más tarde objeto de un amplio desarrollo en el Cours d'Architecture.

16. Artículo Distribution (IV, 1063-1064). 
LA REFERENCIA FRANCESA: ARQUITECTURA Y ARQUITECTOS DESDE LA MIRADA ENCICLOPEDISTA

de batalla de la arquitectura francesa de las Luces ${ }^{17}$. En efecto, la confrontación con la tradición constructiva gótica, que formaba parte del acervo nacional pero chocaba frontalmente con los criterios del clasicismo grecorromano, se convertirá en una piedra de toque a la hora de comprobar en qué medida ese exclusivismo clasicista se iba a poco a poco agrietando para permitir la entrada de otros modos históricos de construir.

Si ya Jean-Louis de Cordemoy había expresado, a principios de siglo, su admiración por las estructuras góticas ${ }^{18}$, el abate Laugier hace lo propio en fechas prácticamente contemporáneas a la colaboración de Blondel para la Encyclopé$d i e^{19}$. En cuanto a este último, el artículo Architecture retoma la diferenciación ya establecida por Jean-François Félibien entre un gothique ancien (basicamente nuestro "románico») y un gothique moderne (el "gótico» propiamente dicho): si el primero es pura barbarie, en el segundo podemos admirar la avanzada técnica constructiva y lamentar al mismo tiempo que tan alto saber se pusiese al servicio de un gusto corrupto. Como desarrollará más tarde en su Cours d'Architecture, Blondel se encuentra ya en los umbrales de esa apreciación del gótico de que enseguida harán gala Soufflot y otros arquitectos de la segunda mitad del XVIII, e incluso llegará a criticar, en una precoz visión patrimonial, la realización de reformas modernas en edificios góticos (ofreciendo el ejemplo a contrario de su propia intervención en la catedral de Metz, respetando el espíritu general del edificio ${ }^{20}$.

Los once volúmenes de grabados con los que se cerró la magna obra representan un espectacular corpus iconográfico del estado de las ciencias, las técnicas y los saberes en las décadas centrales del XVIII. La representación en él de la arquitectura no es muy prolija, pero nos interesa ahora el hecho de que Blondel redactó los comentarios que acompañaban a las 39 láminas que aparecieron en el volumen I de las Planches de la Encyclopédie, bajo el epígrafe de Architecture et Parties qui en Dépendent. Tuvo así ocasión de exponer su pensamiento sobre algunos temas que no desarrolló en artículos. Abordó, por ejemplo, en los 10 primeros grabados, la cuestión de los órdenes clásicos, en cuyo tratamiento introduce un factor de relativismo que cuestiona la rigidez de los cerrados sistemas clasicistas de proporciones y elementos arquitectónicos.

Pero, sobre todo, estas planchas fueron la ocasión para una mayor atención a la arquitectura más estrictamente contemporánea. Blondel comenta, así, críticamente, la célebre fuente de la rue Grenelle, erigida en 1739 por Edmé Bouchardon (y que suscitaría la crítica irónica de Voltaire). Hace gala de su atenta mirada a

17. FrankL, Paul. The Gothic: Literary Sources and Interpretations through Eight Centuries. Princeton, 1960; AA. VV. Le Gothique retrouvé. Catálogo exposición. Paris: CNMHS, 1991; LOveJOY, Arthur O. y BARIDON, Michel. Le gothique des Lumières. Paris: Gerard Monfort, 1991.

18. CORDEMOY, Jean-Louis. Nouveau traité de toute l'architecture, utile aux entrepreneurs, aux ouvriers, et à ceux qui font bâtir. Paris, 1706.

19. Laugier, Marc-Antoine. Essai sur l'Architecture. Paris, 1750 (en especial, pp. 280-281).

20. Blondel, Jacques-François. Cours d'Architecture. Paris: Jombert, 1771, vol. II, p. 211. 
los debates contemporáneos al proponer como modelo de «edificio sagrado» y polo opuesto a la artificiosidad de la arquitectura religiosa barroca el proyecto de Pierre Contant d'Ivry para la Madeleine (profundamente reformado después, como es sabido, por Pierre Vignon) e incluir entre las láminas otro proyecto del propio Contant: la Abbaye Royale de Panthémont, muy próxima a la citada fuente de Bouchardon en ese entorno de la rue Grenelle que concentró algunos de los mejores esfuerzos arquitectónicos de mediados del XVIII en Paris.

Un buen número de láminas, con sus respectivos comentarios, se dedican a los grandes temas de la arquitectura civil. Si el nuevo ideal de grandeza «noble» de la arquitectura pública aparece representado por el hôtel de ville de Rouen, de Le Carpentier, mucho más amplio es el desarrollo dedicado a la arquitectura privada, coherentemente con el interés profesional y teórico de Blondel por la redefinición del hábitat de las élites parisinas. Así, clama por que el arquitecto que construye bôtels urbanos sea él mismo un hombre de mundo, capaz de plasmar en su proyecto la complejidad de la sociabilidad moderna, ofreciendo como ejemplo los planos de un hôtel diseñado por él mismo, al mismo tiempo que elogia la habilidad de los arquitectos franceses para sacar partido de un solar irregular a partir de un ejemplo del arquitecto contemporáneo François Franque. El ya citado Pierre Contant d'Ivry es esgrimido, por último (en la explicación de la Séptima parte de las láminas de arquitectura, titulada «Observations générales sur la décoration intériure»), como ejemplo modélico, en el Palais Royal, de decoración interior que combina el lujo razonable con el principio general de la contención ornamental.

En 1759, como se ha dicho, Jacques-François Blondel siguió a D'Alembert en su abandono de la empresa colectiva. Esa especie de tratado de arquitectura por fragmentos que hubiese sido el corpus completo de sus artículos quedó interrumpido y a falta de algunas de sus partes esenciales. Como en otros muchos ámbitos del conocimiento, Diderot se vio obligado a afrontar esta desesperada situación recurriendo al resto de colaboradores que no habían desertado. Y fue en este punto donde surgió la figura salvadora del Chevalier de Jaucourt, polígrafo increiblemente prolífico y autor en conjunto de más 17.000 artículos para la Encyclopédie, hasta el punto de que hoy se reconoce que la empresa jamás hubiese podido culminarse sin su aportación ${ }^{21}$.

Lo esencial de la contribución de Jaucourt lo encontramos a partir del volumen VII de la Encyclopédie, es decir, justo desde el momento en que se registra la defección de Blondel. Como en muchos otros campos, también en arquitectura el Chevalier corrió a cerrar los huecos que dejaba el abandono de tan distinguido profesional de la arquitectura. Cabría esperar, pues, a priori, un descenso de nivel en la parte arquitectónica de la obra. Sin embargo, por el contrario, lo que se registra es más bien un cambio de horizonte, una apertura de miras: lo que se pierde

21. HAECHLER, John. L'Encyclopédie de Diderot et de... Jaucourt. Essai biographique sur le chevalier Louis de Jaucourt. Paris: Champion, 1995. 
en profesionalidad, se gana en amplitud de referencias culturales y multiplicidad de conexiones de lo arquitectónico con otros ámbitos de la cultura.

En efecto, que Jaucourt no era un diletante frívolo se comprueba a poco que se recorran los centenares de textos arquitectónicos que redactó para los diez últimos volúmenes. Su documentación y sus fuentes son copiosas y variadas porque, aunque para los artículos de índole más técnico-constructiva recurre casi siempre al préstamo directo del por entonces prestigioso Dictionnaire de D'Aviler ${ }^{22}$, en otros textos salen a relucir las más variadas referencias literarias, artísticas, arqueológicas y propiamente arquitectónicas, haciendo gala Jaucourt de un sólido conocimiento de toda la gran tratadística arquitectónica del clasicismo francés, así como de los más importantes textos italianos o ingleses.

En este amplio corpus, el Chevalier desgrana, de manera fragmentaria pero con gran eficacia comunicativa, algunos de los grandes temas de la reflexión ilustrada sobre arquitectura: la relativización del valor de los órdenes clásicos; la reivindicación de la contención ornamental y la consiguiente crítica de los desvaríos del Rococó; la ambigüedad en la consideración de la arquitectura gótica; el desarrollo, al lado de conceptos de largo recorrido como ordonnance o distribution, de otros de más rara aplicación en el ámbito arquitectónico como la vraisemblance, etc.

La asociación entre arquitectura y pensamiento político es mucho más clara en Jaucourt que en Blondel. Tomemos, por ejemplo, la gran cuestión del gótico, ya comentada a propósito de Blondel. Aunque no es Jaucourt quien escribe el artículo Gothique ${ }^{23}$, sino el abate Mallet, las tesis de ambos son coincidentes: la arquitectura gótica ha de ser objeto de condena por contraria a la naturaleza, alejada de los antiguos y, además, directamente ligada al oscurantismo feudal. Así, en el artículo Temples (Hist. des Arts) ${ }^{24}$, queda claro que el modelo de Jaucourt sigue siendo el templo griego, ejemplo a un tiempo de simplicidad y magnificencia directamente derivadas de su origen natural. Es el cristianismo el que da inicio a una decadencia en la que la arquitectura abandona la simplicidad y cae en la falta de verdad. Y, sin embargo, ni Mallet ni Jaucourt pueden sustraerse por completo al sentimiento ya expresado por Cordemoy, por el abate Laugier o por el propio Blondel: la admiración por el sistema constructivo gótico y la experimentación de una emoción que a menudo es sentida con culpabilidad. En ese mismo artículo, Jaucourt se preguntará, ante una catedral gótica, «... mediante qué destreza asombrosa había podido edificarse un edificio tan poco sustentado y que, sin embargo, se mantiene en pie desde hace varios siglos». Poco a poco este asombro irá transmutándose -en paralelo a la difusión en Francia de las tesis estética procedentes

22. D'Aviler, Charles Augustin. Cours d'Architecture. Paris, 1691.

23. VII, 749.

24. XVI, 62-63. 
de Inglaterra- en admiración cada vez menos disimulada, hasta culminar en los experimentos "greco-góticos" ${ }^{25}$ de Soufflot.

La manera en que la crítica política influye sobre las valoraciones arquitectónicas se deja ver también en las consideraciones de Jaucourt sobre los grandes edificios del Grand Siècle de Luis XIV, marcadas por esa actitud casi general entre los enciclopedistas tendente a salvar ciertos aspectos del periodo del Rey Sol para oponerlos enfáticamente a la degeneración de la Regencia y Luis XV. La complejidad de esta actitud puede entenderse si comparamos los artículos Louvre ${ }^{26}$ y Versailles $^{27}$, escritos ambos por Jaucourt. En el primero de ellos, el Chevalier aúna la valoración sin reservas del clasicismo arquitectónico de Perrault con un encendido elogio de la organización cultural centralizada del Rey Sol. Y propone todo un programa de terminación y reutilización del edificio en el marco de una ciudad soñada entregada a la cultura: limpieza y porticado de todas las plantas bajas, colocación en estos pórticos de "las más bellas estatuas", disposición en la zona sur de los cuadros del rey ( disfruta de ellos»), instalación de los Cabinets des Medailles y de Histoire Naturelle, ubicación igualmente de las diversas Academias del reino y, por último y sobre todo, reordenación urbanística de todo el entorno de Saint-Germain para permitir la libre visión monumental de la columnata.

El artículo Versailles nos deja ver, sin embargo, cómo esta mitificación del reinado de Luis XIV encuentra sus límites cuando colisiona con la crítica política: si el Louvre puede recuperarse como símbolo de un cierto absolutismo humano matizado por los afanes culturales, Versalles es siempre, por el contrario, el símbolo de la desmesura, el lugar donde el desdenfreno y el derroche triunfan sobre la razón y sobre la grandeza bien entendida: una "vorágine de gastos y magnificencia» en la que el buen y el mal gusto se entremezclan de modo indiscriminado. El lugar, en suma, donde las pasiones sin freno triunfan sobre la razón.

Pero es quizás en los numerosos artículos dispersos que tratan sobre arquitecturas ajenas a la tradición europea donde mejor se revela el discurso estéticopolítico que con frecuencia prima sobre la pura reflexión arquitectónica en los textos de Jaucourt. Las arquitecturas orientales se encuentran en el cruce entre líneas de pensamiento de tanta trascendencia ideológica y política como son la «teoría de los climas» (desarrollada por personajes como Montesquieu o el abate $\mathrm{Du}$ Bos $)^{28}$, la construcción teórica del "despotismo oriental», la mitificación de

25. Middleton, Robin. "The abbé de Cordemoy and the Graeco-Gothic Ideal: a Prelude to Romantic Classicism». Journal of the Warburg and Courtauld Institutes, 1962, XXV, pp. 287-320.

26. IX, 706-707.

27. XVII, 162.

28. Así, por ejemplo, en el artículo Inde insiste, siguiendo a Montesquieu, en la interrelación entre clima, religión y costumbres y relaciona con el clima agobiante la pasividad de los hindúes y los gobiernos tiránicos que soportan, aunque no deja de describir con cierta simpatía la delicadeza de sus artes decorativas. 
LA REFERENCIA FRANCESA: ARQUITECTURA Y ARQUITECTOS DESDE LA MIRADA ENCICLOPEDISTA

ciertos aspectos de las culturas orientales (y en particular el espejismo chino) o las reflexiones sobre la idea de progreso y la desigualdad de su desarrollo entre los distintos pueblos.

Un rasgo común de los artículos en los que Jaucourt aborda la descripción de arquitecturas orientales es el negarles un análisis estético similar al que se pone en práctica para los edificios europeos: anticipando algo que desarrollará hasta un grado extremo el discurso orientalista decimonónico, calificativos como "agradable» o "gracioso" delimitan el vocabulario de una apreciación de segundo grado que no se considera digna de las categorías estéticas centrales del clasicismo occidental. Así, por ejemplo, el artículo Temples des chinois ${ }^{29}$ valora positivamente la «industriosidad» del pueblo chino para transformar áridos parajes en lugares idílicos donde ubicar sus templos, pero elude cualquier descripción arquitectónica de éstos. O bien el artículo Kiosche ${ }^{30}$ se centra en el carácter "agréable» de estos edículos orientales, pero considerándolos al mismo tiempo símbolos del lujo corruptor.

Quizás el texto más interesante en esta línea sea el largo artículo Serrail ${ }^{\beta 1}$, en el que describe Jaucourt el palacio del Serrallo de Constantinopla unificando la crítica del gusto arquitectonico islámico y del sistema político del despotismo oriental. En su opinión, en el Serrallo no se puede encontrar «... nada de lo que llamamos soberbio y magnífico, porque los turcos apenas saben lo que es la magnificencia en materia de edificios y no siguen ningun regla de buena arquitectura». El palacio no es, en realidad, más que un cúmulo de recargadas estancias fruto del capricho arbitrario de los sucesivos sultanes, sin plan ni orden. Si hay en él algo bueno, se debe o al modelo de Santa Sofía ${ }^{32}$ o a los objetos traídos por embajadores occidentales. Es, en suma, el tipo de edificación adecuada a la corrupción de las cortes orientales ( $«$ gentes que no temen más que al trabajo pueden encontrar su felicidad en lugares donde no hay nada que hacer») y la prisión dorada de las desgraciadas habitantes del harén.

Esta misma coexistencia tensa entre ideas radicalmente innovadoras y pervivencia de categorías aún ancladas a la estética del clasicismo puede apreciarse, por último, en el tratamiento que a lo largo de los volúmenes de la Enciclopedia se da a la cuestión del jardín ${ }^{33}$. En este terreno, la fuerza del paradigma del jardín geométrico a la francesa era aún muy importante en las décadas centrales del XVIII, pero ya comenzaban a vislumbrarse los avances de la estética de lo pintoresco procedente del otro lado de la Mancha, de la que enseguida se haría eco

29. XVI, 82-83.

30. IX, 130 .

31. XV, 114-116.

32. En el artículo Sophie, Sainte (XV, 362-363), Jaucourt da una detallada descripción histórica del edificio que culmina con la condena de las transformaciones turcas: «Pero, como son enemigos de las artes, han destruido o dejado perecer la mayor parte de este antiguo templo y sus decoraciones».

33. Perkins, J. A. "Gardening in the Encyclopédie». Diderot Studies, 1978, XIX, pp. 145-162. 
Rousseau y que daría lugar a realizaciones tan notables como el Désert de Retz o Ermenonville.

En la Encyclopédie, un buen número de los artículos que tratan sobre jardines abordan tan sólo aspectos botánicos o hidraúlicos. En su mayoría de trata de artículos anónimos tomados de La théorie et la pratique du jardinage (1709) de Antoine-Joseph Dezallier d'Argenville, el más importante codificador, ya en plena centuria ilustrada, del sistema de Le Nôtre. En este grupo de textos se suele dar por sentada e indiscutida la disposición geométrica del "jardín a la francesa", algo que queda más patente aún en las planches de jardines ${ }^{34}$.

Pero, junto a ellos, existe un segundo grupo de artículos, firmados por ese polígrafo inagotable que fue el Chevalier de Jaucourt. En ellos se deja a un lado el terreno técnico para pasar a abordar la cuestión paisajística en sus más profundas implicaciones filosóficas y estéticas, dando amplia entrada a las nuevas concepciones del jardín paisajístico inglés.

Jaucourt conocía muy bien la cultura británica y la renovación en la concepción del paisaje que se había articulado en torno a la filosofía del asociacionismo y el empirismo y en torno a figuras como Pope, Addison o Thomson. James Thomson era, en concreto, uno de los principales representantes de la poesía «estacional» -exaltadora de lo cambiante y lo pasajero en la naturaleza- británica, con su poema Seasons (1726), que había sido traducido al francés en 1759 y que encontraría su réplica gala en Les Saisons escritas por otro enciclopedista, el marqués de Saint-Lambert.

La importancia que la pasión de Jaucourt por la poesía de Thomson tuvo para la transmisión a Francia del pintoresquismo inglés se deja ver con claridad en numerosos artículos de la Enciclopedia, la mayoría posteriores a la gran ruptura de 1759 que alejó de la empresa a los elementos más ligados a la pervivencia del clasicismo. En Saisons, Temple o Soleil Jaucourt cita explicitamente a Thomson en apoyo de una concepción del jardín como lugar de comunión con la naturaleza, de ejercitación simultánea de los poderes de la inteligencia y de las fuerzas del sentimiento. En el artículo Sage, Le reinterpreta, así, el viejo tema de la retirada del sabio haciendo del jardín natural el lugar en el que se cumple el reposo espléndido del alma y ésta puede sustraerse al movimiento tormentoso de las pasiones y oír la tempestad mundana desde despagada distancia. Igualmente patente es la influencia de Addison (por ejemplo, todo el artículo Description no es sino una perífrasis de los célebres Pleasures of Imagination).

Algunos artículos de Jaucourt reflejan de manera especial esta penetración del nuevo sentimiento de la naturaleza. Así, en Plantation ${ }^{35}$ llega a afirmar

34. Ejemplos destacados de este tipo de artículos son los titulados Arbre, Palissade o Parterre. En cuanto a las láminas sobre jardines, se encuentran en el vol. I de las Planches, bajo el epígrafe Agriculture, Jardinage.

35. XII, 710-712. 
taxativamente: «No hay que preocuparse demasiado por la simetría de las plantaciones. Todo el mundo puede colocar árboles alineados y ordenados, en damero o con cualquier otra figura uniforme. Pero, ¿acaso debemos limitarnos a esa regularidad sin osar apartarnos de ella? ¿No sería mejor ocultar a veces el arte del jardinero?». Y en Symmétrie des Plantations propone huir de los jardines geométricos porque la simetría es enemiga de la naturaleza y de la variedad, al tiempo que declara ya sin ambages la superioridad del jardín inglés sobre el francés: «El gusto por los puntos de vista lejanos viene de la tendencia de la mayoría de los hombres a no complacerse más que allá donde no están; ávidos de lo que se encuentra lejos de ellos, el artista, que no puede contentarlos con lo que les rodea, les ofrece siempre perspectivas para entretenerlos; pero el hombre del que yo hablo no tiene necesidad de este recurso y, cuando se ocupa del espectáculo de las bellezas de la naturaleza, no se preocupa de las gentilezas del arte. En el parque de Saint James el lápiz se le cayó de las manos a Le Nôtre, asombrado y confundido de ver realmente lo que ofrece todo el conjunto de la vida en la naturaleza y de interés para su espectador ${ }^{36}$.

Todas estas reflexiones se sintetizan, finalmente, en el artículo Jardin ${ }^{37}$, en el que Jaucourt hace coexistir el elogio de Le Nôtre con la dura crítica a los excesos de sus seguidores, situándose así en esa clara línea de la mayoría de los enciclopedistas tendente a salvar el núcleo principal de la cultura del clasicismo contraponiéndolo a las "degeneraciones» irracionales del Rococó, presa de esa gran lacra a un tiempo moral y estética que es la frivolité. Jaucourt puede así, al mismo tiempo que propone jardines a la inglesa, salvar un hipotético "verdadero» jardín francés, esgrimido como un mito del pasado contra las corrupciones de la cultura contemporánea.

\section{BiBLIOGRAFÍA}

AA. VV. Le Gothique retrouvé. Catálogo exposición. Paris: CNMHS, 1991.

BARÓN, Javier. Ideas de Jovellanos sobre la arquitectura. Oviedo: Consejería de Educación, Cultura y Deportes del Principado de Asturias, 1985.

Calatrava, Juan. La teoría de la Arquitectura y de las Bellas Artes en la Encyclopédie de Diderot y D'Alembert. Granada: Diputación Provincial, 1992.

CALATRAVA, Juan. «Una propuesta de enseñanza de la arquitectura en la Francia de las Luces: Blondel y la École des Arts». En AA. VV. Estudios dieciochistas en homenaje al profesor José Miguel Caso González. Oviedo: Instituto Feijoo de Estudios del siglo XVIII, 1995, pp. 118-127.

36. $\mathrm{XV}, 735$.

37. VIII, 459-460. 
CHEMINADE, Christian. "Architecture et médecine à la fin du XVIIIe siècle: la ventilation des hôpitaux, de l'Encyclopédie au débat sur l'Hôtel-Dieu de Paris». En Recherches sur Diderot et l'Encyclopédie, 1993, 14, pp. 85-109.

CLEARY, Richard Louis. Jacques-François Blondel and the notion of architectural convenience. Madison: University of Wisconsin, 1977.

CRESPo Delgado, Daniel. Un viaje para la Ilustración. El Viaje de España (1772-1794) de Antonio Ponz. Madrid: Marcial Pons, 2012.

DiDi-Huberman, Georges. La imagen superviviente. Historia del arte y tiempo de los fantasmas según Aby Warburg. Madrid: Abada editores, 2009.

Francastel, Pierre. "L'esthétique des Lumières». En Francastel, Pierre (ed.). Utopie et institutions au XVIII siècle. Le pragmatisme des Lumières. Paris-La Haya: Mouton, 1963, pp. 331-357 (traducción castellana "La estética de las Luces». En AA. VV. Arte, arquitectura y estética en el siglo XVIII. Madrid: Akal, 1980, pp. 15-55).

FRANKL, Paul. The Gothic: Literary Sources and Interpretations through Eight Centuries. Princeton, 1960.

HAECHLER, John. L'Encyclopédie de Diderot et de... Jaucourt. Essai biographique sur le chevalier Louis de Jaucourt. Paris: Champion, 1995.

LeÓn Tello, Francisco José y SANZ SANZ, M. ${ }^{a}$ Virginia. Estética y teoría de la arquitectura en los tratados españoles del siglo XVIII. Madrid: CSIC, 1994.

Lovejoy, Arthur O. y Baridon, Michel. Le gothique des Lumières. Paris: Gerard Monfort, 1991.

Middleton, Robin. "The abbé de Cordemoy and the Graeco-Gothic Ideal: a Prelude to Romantic Classicism». Journal of the Warburg and Courtauld Institutes, 1962, XXV, pp. 287-320.

Molé́n, Pedro. Arquitectos españoles en la Roma del Grand Tour (1746-1796). Madrid: Abada editores, 2003.

Perkins, J. A. "Gardening in the Encyclopédie». Diderot Studies, 1978, XIX, pp. 145-162.

PÉRouse De Montclos, Jean-Marie. L'Architecture à la Française. XVI $, X V I I^{\circ}, X V I I I^{\mathrm{e}}$ siècles. Paris: Picard, 1982.

Proust, Jacques. Diderot et l'Encyclopédie. Paris: Albin Michel, 1962.

Rodríguez Ruiz, Delfín. La memoria frágil. José de Hermosilla y Las Antigüedades árabes de España. Madrid: Fundación Cultural COAM, 1992.

Rodríguez Ruiz, Delfín (ed.). José de Hermosilla y Sandoval. Badajoz: Diputación Provincial, 2015.

SAmBricio, Carlos. La arquitectura española de la Ilustración. Madrid: Consejo Superior de los Colegios de Arquitectos de España-Instituto de Estudios de Administración Local, 1986.

SAmbricio, Carlos. Territorio y ciudad en la España de la Ilustración. Madrid: Ministerio de Obras Públicas y Transportes, 1991.

SCHLÖGEL, Karl. En el espacio leemos el tiempo. Madrid: Siruela, 2007, p. 165.

Úbeda De los CoBos, Andrés. Pensamiento artístico español del siglo XVIII. De Antonio Palomino a Francisco de Goya. Madrid: Museo Nacional del Prado, 2001. 